Original Research Article

\title{
Comparison of safety pattern of drugs used in chronic obstructive pulmonary disease patients in a tertiary care hospital
}

\author{
Dharmaraj B. ${ }^{1}$, Abhijith L. M. ${ }^{1}{ }^{*}$, Jagadeesh K. ${ }^{1}$, Basavaraj S. ${ }^{2}$
}

${ }^{1}$ Department of Pharmacology,

${ }^{2}$ Department of Pulmonary

Medicine, Basaveshwara

Medical College and Hospital,

Chitradurga, Karnataka, India

Received: 18 June 2019

Accepted: 31 July 2019

*Correspondence to:

Dr. Abhijith L. M.,

Email: drabhijithlm@gmail.com

Copyright: (C) the author(s), publisher and licensee Medip Academy. This is an openaccess article distributed under the terms of the Creative Commons Attribution NonCommercial License, which permits unrestricted noncommercial use, distribution, and reproduction in any medium, provided the original work is properly cited.

\begin{abstract}
Background: As per GOLD (Global initiative for chronic obstructive lung disease) guidelines bronchodilators are required for symptomatic treatment of chronic obstructive pulmonary disease (COPD) patients. Currently there is no evidence to say about the safety of fixed dose combinations used in COPD patients. Since the drugs are to be taken for longer period, it is essential to know the safety aspects of these drugs. Moreover we don't have adequate studies and documentation to say that a particular drug combination is better and safer for COPD patients.

Methods: Prospective, open labelled, randomized, comparative, interventional clinical study conducted by the Departments of Pharmacology and Pulmonary Medicine of Basaveshwara Medical College and Hospital, Chitradurga in 40 COPD patients.

Results: The fixed dose combinations of drugs used in both the treatment groups i.e. salmeterol/fluticasone and tiotropium/formoterol were equally safer and well tolerated. Some side effects noticed during the course of treatment were statistically significant when compared between the 2 groups, however they were milder and predictable adverse drug reactions.

Conclusions: Systemic and severe adverse drug reactions were not observed during 8 week treatment period and the local side effects observed were mild in both the treatment groups. Hence the fixed dose combinations of salmeterol or fluticasone and tiotropium or formoterol are found to be safer for maintenance therapy in COPD patients.
\end{abstract}

Keywords: Adverse drug reactions, Safety, LABA, ICS, COPD, GOLD

\section{INTRODUCTION}

Chronic obstructive pulmonary disease (COPD) is one of the most common chronic respiratory disorder across the world. It's the fourth leading cause of death in the world and is projected to be $3 \mathrm{rd}$ by $2020 .{ }^{1}$ This trend is due to the risk factors and the changing age structure of the world's population (with more people living longer, and thus reaching the age at which COPD normally develops). ${ }^{2}$

Maintenance therapies for COPD that are recommended in widely accepted clinical guidelines include long-acting beta-agonists (LABAs) alone, inhaled corticosteroids (ICS) alone, ICS plus LABA, and anticholinergic agents. ${ }^{3}$ The use of appropriate medications for the treatment of COPD is essential to improve patient quality of life and minimize the substantial burden of illness that COPD places on the health care system. ${ }^{4}$ For patients whose COPD is not sufficiently controlled by monotherapy, combining a B2-agonist with either inhaled steroid or anticholinergic drug is a convenient way of delivering treatment and obtaining better lung function and improved symptoms. ${ }^{4,5}$

Currently, there is no documentation that one is superior to other or the contrary, but a combination of two drugs is 
more effective than giving single drug alone in inducing bronchodilation in patients suffering from COPD. ${ }^{6,7}$ Monitoring of adverse drug reactions is very important to assess the clinical outcome. Moreover reporting the adverse drug reactions (ADRs) and treating them will improve the compliance and adherence to the treatment.

The purpose of the present study is to identify both immediate and short term side effects that might be seen during the course of the treatment. Since there were limited studies to comment on the safety profile of drugs used in COPD patients, this study was undertaken.

\section{Aims and objectives}

The aim and objective of the study was to compare safety pattern of two fixed dose combinations i.e. salmeterol and fluticasone vs. formoterol and tiotropium bromide in COPD patients.

\section{METHODS}

The study was conducted after the approval issued by Institutional Ethics Committee (Ref. BMC \& H / IEC /2018-2019/09)

\section{Study Protocol}

This is a prospective, open labelled, randomized, comparative, interventional clinical study conducted by the Departments of Pharmacology and Pulmonary Medicine, Basaveshwara Medical College \& Hospital, Chitradurga in 40 COPD patients. Study was in accordance with the principles of good clinical practice and declaration of Helsinki. Written informed consent was obtained from all the patients enrolled for the study.

\section{Study sample}

Two groups each of 20 moderate to severe COPD patients of either sex were randomly allocated to receive two different FDC regime treatments. The patients were screened for eligibility in the out-patient clinic, Department of Pulmonary Medicine according to following inclusion and exclusion criteria.

\section{Inclusion criteria}

Inclusion criteria were 20-75 years of age of either sex; clinically diagnosed cases of COPD of moderate to severe variety as per GOLD criteria (Table 1); requirement of combination of LABA and ICS and LABA with long acting anticholinergic; patients ready to provide written informed consent to the study protocol

\section{Exclusion criteria}

Exclusion criteria were patients of bronchial asthma; pregnant and lactating woman; routine use of nebulised bronchodilator therapy; unstable concurrent medical problems like uncontrolled hypertension, diabetes mellitus, pulmonary tuberculosis.

Table 1: Classification of severity of airflow limitation in COPD patients.

\begin{tabular}{|lll|} 
Stage & Severity & $\begin{array}{l}\text { Patients with FEV1/FVC } \\
<\mathbf{0 . 7 0}\end{array}$ \\
\hline GOLD 1 & Mild & FEV $1 \leq 80 \%$ predicted \\
\hline GOLD 2 & Moderate & $50 \% \leq \mathrm{FEV} 1<80 \%$ predicted \\
\hline GOLD 3 & Severe & $30 \% \leq \mathrm{FEV} 1<50 \%$ predicted \\
\hline GOLD 4 & Very severe & FEV $1<30 \%$ predicted \\
\hline
\end{tabular}

\section{Drug treatment}

The patients were randomly assigned with the help of enveloped grouping system to get allotted to either of two groups:

Group I: Salmeterol $25 \mu \mathrm{g}$ and fluticasone $250 \mu \mathrm{g}$ (SEROFLO 2 puffs b.d by inhalation) for a period of 8 weeks

Group II: Formoterol $12 \mu \mathrm{g}$ and tiotropium bromide $9 \mu \mathrm{g}$ (DUOVA 2 puffs o.d by inhalation) for a period of 8 weeks

Available commercial preparations (same brand) were used throughout the study period. SEROFLO and DUOVA, Metered Dose Inhalers marketed by CIPLA limited were used.

\section{Clinical assessment}

It was carried out in all the patients in terms of safety of the treatment.

\section{Safety assessment}

The patients were assessed every 2 week for 8 weeks to check the occurrence of adverse drug reactions.

\section{Data collection}

The data collection was prospective in nature. The period of observation was for 8 weeks on one therapeutic regime. Eligible subjects were interviewed and Information was collected regarding the safety use of two different fixed dose combinations.

\section{Data analysis}

The data obtained were expressed as Mean \pm standard error of mean (SEM). For intergroup, unpaired T test was used to analyse categorical variables, where ever appropriate. $\mathrm{P}<0.05$ was considered as statistically significant. All statistical analysis was performed with the use of SPSS software package. 


\section{RESULTS}

\section{Safety assessment}

It was done by monitoring the adverse drug reactions reported during the course of treatment in both the groups

On week 4, sore throat was seen in 2 patients in group II. On week 6 , two patients in group I and three patients in group II had similar reaction. On week 8, four patients in group I and three patients in group II had sore throat but none of them are statistically significant.

No adverse effects were observed till 4 week in both groups. On week 4, one patient in group 1 and three patients in group II had dryness of mouth. On week 8, six patients in group II had dry mouth which was significant compared to group I as shown in Table 2.

Table 2: Incidence of adverse drug reactions in two treatment groups.

\begin{tabular}{|c|c|c|c|c|c|c|c|c|c|c|}
\hline \multirow{4}{*}{$\begin{array}{l}\text { Adverse drug reactions } \\
\text { (ADRs) }\end{array}$} & \multirow{2}{*}{\multicolumn{2}{|c|}{$\begin{array}{l}\text { 0 week } \\
\text { Groups }\end{array}$}} & \multirow{2}{*}{\multicolumn{2}{|c|}{$\begin{array}{l}\text { Week } 2 \\
\text { Groups }\end{array}$}} & \multirow{2}{*}{\multicolumn{2}{|c|}{$\begin{array}{l}\text { Week } 4 \\
\text { Groups }\end{array}$}} & \multirow{2}{*}{\multicolumn{2}{|c|}{$\begin{array}{l}\text { Week } 6 \\
\text { Groups }\end{array}$}} & \multirow{2}{*}{\multicolumn{2}{|c|}{$\begin{array}{l}\text { Week } 8 \\
\text { Groups }\end{array}$}} \\
\hline & & & & & & & & & & \\
\hline & I & II & I & II & I & II & I & II & I & II \\
\hline & $\mathbf{N}(\%)$ & $\mathbf{N}(\%)$ & $\mathbf{N}(\%)$ & $\mathbf{N}(\%)$ & $\mathbf{N}(\%)$ & $\mathbf{N}(\%)$ & $\mathbf{N}(\%)$ & $\mathbf{N}(\%)$ & $\mathbf{N}(\%)$ & $\mathbf{N}(\%)$ \\
\hline Dry mouth & 0 & 0 & 0 & 0 & $1(5)$ & $3(15)$ & $1(5)$ & $5(25)^{*}$ & $1(5)$ & $6(30)^{*}$ \\
\hline Sore throat & 0 & 0 & 0 & 0 & 0 & $2(10)$ & $2(10)$ & $3(15)$ & $4(20)$ & $3(15)$ \\
\hline Hoarseness of voice & 0 & 0 & 0 & 0 & $1(5)$ & $1(5)$ & $5(25)$ & $2(10)$ & $3(15)$ & $5(25)$ \\
\hline Oro-pharyngeal candidiasis & 0 & 0 & 0 & 0 & 0 & 0 & $1(5)$ & 0 & $5(25)^{*}$ & $1(5)$ \\
\hline Other ADRs & 0 & 0 & 0 & 0 & 0 & 0 & 0 & 0 & 0 & 0 \\
\hline
\end{tabular}

All values are expressed as total number of patients (\%) Intergroup analysis: *Comparison between values of Group-I and Group-II at respective week $(\mathrm{p}<0.05)$.

On week 4, hoarseness of voice was noticed in one patient in both groups. Later five patients in group I and two in group II developed similar reaction on week 6. However, on week 8 , three patients in group I and five patients in group II had similar complaints.

On week 6, candidiasis was found in one patient in group I. Furthermore, on week 8 , five patients had similar reaction in group I and were significant compared to group II as shown in Table 2.

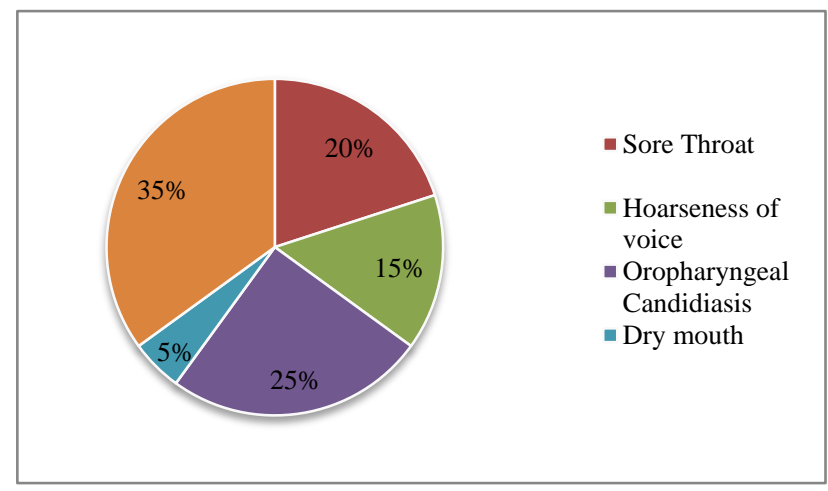

Figure 1: Incidence of ADR's in group I at the end of week 8.

At the end of week 8, 35\% in group I and $25 \%$ in group II didn't have any ADR's during the course of treatment as shown in Figure 1 and 2 respectively.

Incidence of ADR's in both treatment group I and II at the end of week 8 is shown in Figure 1 and 2 respectively.

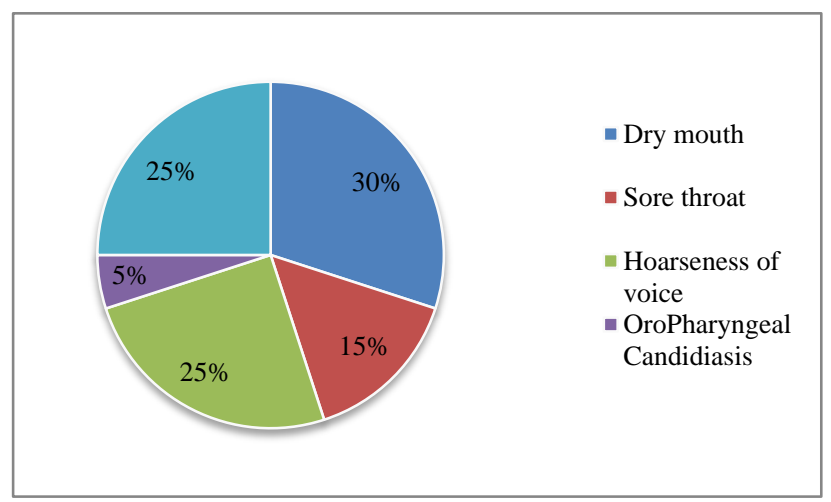

Figure 2: Incidence of ADR's in group ii at the end of week 8.

Both the treatments were well tolerated. During 8 weeks of treatment, serious ADR's were not reported. Discontinuations due to adverse effects were rare in both the groups.

\section{DISCUSSION}

The present study was conducted in a prospective randomized manner to compare the safety pattern of two treatment groups i.e. salmeterol and fluticasone vs. formoterol and tiotropium bromide in moderate to severe COPD patients. The patients were observed for a period of 8 weeks, during this period patient compliance was good and were responding well to the treatment. The results of the present study showed that there was progressive improvement in lung function right from the beginning of the study. 
Hoarseness of voice was experienced in some patients in both the group which could be attributed to the local side effects of the drugs used in both the groups. Oral candidiasis was noticed from $6^{\text {th }}$ week in group 1 patient which increased in few more patients at the end of $8^{\text {th }}$ week. This side effect may be due to use of inhaled steroid or maybe due to improper use of inhaler. Though mild local side effects were noticed during 8 week treatment period in both the treatment groups, systemic side effects were absent. Thus both the FDCs are found to be safer to an extent.

Our observation during the study revealed a reassuring safety profile of both the FDCs without the increased incidence of adverse events or serious adverse events. Our study has several limitations. A long term study might have helped us to fully examine the other unknown side effects of these FDCs on the incidence of exacerbations.

Hanania et al in their study investigated the benefits of adding fluticasone propionate or salmeterol to tiotropium in moderate to severe COPD patients. ${ }^{8}$ The study concludes That addition of Fluticasone to subjects with COPD treated with Tiotropium significantly improves lung function without increasing the risk of adverse events.

The overall results of the present study show that both the treatments i.e. salmeterol or fluticasone and tiotropium or formoterol were equally safer. However the combination, salmeterol or fluticasone was found to be better tolerated than tiotropium or formoterol for moderate to severe COPD patients.

\section{CONCLUSION}

As far as the safety profile is concerned both the FDCs (fixed dose combinations) were safer and well tolerated by COPD patients as no systemic side effects were observed during 8 week treatment period. Local side effects observed were mild and predictable with the dose used. Hence the fixed dose combinations of salmeterol or fluticasone and tiotropium or formoterol are found to be safer for maintenance therapy in moderate to severe COPD patients.

Funding: No funding sources Conflict of interest: None declared

Ethical approval: The study was approved by the Institutional Ethics Committee (Ref. BMC \& H/IEC /2018-2019/09)

\section{REFERENCES}

1. Lozano R, Naghavi M, Foreman K. Global and regional mortality from 235 causes of death for 20 age groups in 1990 and 2010: a systematic analysis for the Global Burden of Disease Study 2010. Lancet. 2012;380(9859):2095-128.

2. Global Initiative for Chronic Obstructive Lung Disease. Global strategy for the diagnosis, management, and prevention of chronic obstructive pulmonary disease (Online). Updated 2018. Available at: http://www.goldcopd.org/Guideline Item.asp. Accessed on 3 June 2019.

3. Lopez AD, Shibuya K, Rao C, Mathers CD, Hansell AL, Held LS, et al. Chronic obstructive pulmonary disease: current burden and future projections. Eur Respir J. 2006;27:397-412.

4. Anthonisen NR, Skeans MA, Wise RA, Manfreda J, Kanner RE, Connett JE. The effects of a smoking cessation intervention on 14.5-year mortality: a randomized clinical trial. Ann Intern Med. 2005;142:233-9.

5. Celli BR, MacNee W. ATS/ERS Task Force. Standards for the diagnosis and treatment of patients with COPD: A summary of the ATS/ERS position paper. Eur Respir J. 2004;23:932-46.

6. Oostenbrink JB, Rutten-van Mölken MP, Al MJ, van Noord JA, Vincken W. One-year cost-effectiveness of tiotropium versus ipratropium to treat chronic obstructive pulmonary disease. Eur Respir J. 2004;23:241-9.

7. Wedzicha JA, Calverley PMA, Seemungal TA. The prevention of chronic obstructive pulmonary disease exacerbations by salmeterol/ fluticasone propionate or tiotropium bromide. Am J Respir Crit Care Med. 2008;177:19-26.

8. Hanania NA, Crater GD, Morris AN. Benefits of adding fluticasone propionate/salmeterol to tiotropium in moderate to severe COPD. J Respir Med. 2012;106:91-101.

Cite this article as: Dharmaraj B, Abhijith LM, Jagadeesh K, Basavaraj S. Comparison of safety pattern of drugs used in chronic obstructive pulmonary disease patients in a tertiary care hospital. Int J Basic Clin Pharmacol 2019;8:2060-3. 